\title{
Quanto de Inusitado Guarda uma Sala de Aula de Matemática? Aprendizagens e erro
}

\section{How unusual a Mathematics class can be? Learning processes and mistakes}

\author{
Sônia Maria Clareto* \\ Aline Aparecida da Silva ${ }^{* *}$
}

\begin{abstract}
Resumo
Uma aula de matemática em uma escola pública: uma escola comum, uma sala de aula comum. Tudo corre como de costume. Porém, uma atenção fina a uma pequena e banal situação pode constituir um olhar atento a sutilezas desta sala de aula de matemática. Na correção de uma lista de tarefas de casa, uma aluna se complica, um professor explica... Quanto de implicação cabe neste episódio? Nesta pacata sala de aula de matemática um "erro" é inaugurado como produção. Uma trama com a sala de aula, com a matemática, com o mínimo e sua potência. Um desvio é tomado como uma aprendizagem junto à matemática. Escape à reprodução de um modelo que se coloca como caminho que leva ao resultado correto. Invenção de um modo de operar que inquieta um pensamento, engendrando um pensar que rompe com um modo já normatizado. Este artigo surge junto a uma dissertação de mestrado em Educação. Na pesquisa que gera a dissertação, há um colocar-se junto à sala de aula de matemática em abertura aos acontecimentos que ali vão se dando.
\end{abstract}

Palavras-chave: Aprendizagem. Erro. Sala de aula de matemática.

\begin{abstract}
A mathematics class in a public school: a usual school, a usual classroom. Everything flows as normal. However, an accurate attention to a small and trivial situation may constitute a watchful eye to simplicities in this mathematics class. As the homework was corrected, a student has doubts, the teacher explains... How consequent is this episode? In this quiet mathematics class a "mistake" is opened as production. A plot like a mathematics class, with the minimum of its potency. A deviation is taken as learning along with mathematics. An escape to reproduction of a model that stands, as a way that leads, to the correct result. The invention of an operation method that disquiet a thought, idealizing a thinking that breaks with the previous abordation. This article appears next to a master's dissertation in Education. In the research that generates the dissertation, there is a place beside the mathematics class in opening up to happening that there will giving.
\end{abstract}

Keywords: Learning. Mistakes. Mathematics Classroom.

Eu quero mais erosão menos granito O que é bonito, (Lenine e Marcos Suzano, O que é bonito?, Olho de peixe,1993)

\footnotetext{
* Doutora em Educação Matemática pela Universidade Estadual Paulista (UNESP). Professora Associada da Universidade Federal de Juiz de Fora (UFJF), Juiz de Fora/MG, Brasil. Endereço para correspondência: Rua José Lourenço Kelmer, s/n, Campus Universitário, Bairro São Pedro, CEP: 36036-900, Juiz de Fora/MG, Brasil. E-mail: sclareto@yahoo.com.br.

${ }^{* *}$ Mestre em Educação pela Universidade Federal de Juiz de Fora (UFJF). Endereço para correspondência: Rua José Lourenço Kelmer, s/n, Campus Universitário, Bairro São Pedro, CEP: 36036-900, Juiz de Fora/MG, Brasil. E-mail: alinesilva.mat@gmail.com.
} 
O sinal toca ${ }^{1}$. Os professores continuam sentados, sabem que os alunos não irão imediatamente para suas salas. O final do recreio tem uma dinâmica própria: os alunos correm para beber água, ir ao banheiro, terminar a conversa, terminar de lanchar... Criam movimentos de prolongamento, fazendo com que aquele momento perdure por mais tempo... Os funcionários da escola começam a incumbência de encaminhar os alunos para suas salas. Alguns instantes depois, os professores seguem para as salas e se juntam aos funcionários para, enfim, conseguir que todos os alunos entrem. Dentro das salas, os alunos vão se organizando devagar. Demoram a romper com o movimento do recreio, o que costuma deixar alguns professores irritados. Um professor de matemática parece não querer perder tempo: aproveita essa morosidade dos alunos para ajeitar seu material e escrever no quadro a lista de tarefas, organizada da letra a) à j), que será corrigida e que fora deixada como dever de casa, na aula anterior:

Achar o valor numérico das expressões abaixo,

Considerando $x=1, y=2$ e $z=3$

a) $4 x+3 y+2 z$

b) $x y z+3 x+2 y z$

...

Alguns alunos, ao perceberem o quadro preenchido, abrem seus cadernos já à espera da correção; outros abrem seus cadernos e, continuando a conversa, copiam os escritos do quadro sem perceberem que se referem à lista já passada; outros, ainda, aproveitam que o professor está de costas para a turma, escrevendo no quadro, e fingem não ver que o quadro já está ocupado com uma lista de tarefas. Há aqueles que, envolvidos ainda no movimento do recreio, não percebem que a aula começara... Um aluno chega atrasado do recreio e entra. $\mathrm{O}$ professor o deixa entrar, mas adverte que é necessário pedir licença. Terminando de escrever, o professor pede a atenção da turma: -Vamos, gente! Abram os cadernos vamos fazer a correção!!. Pede mais algumas vezes até conseguir que todos entrem no movimento por ele desejado. Um aluno, que havia percebido que copiava em vão, arranca a folha, faz uma bolinha e a lança em um colega. Alguns ainda mexem no celular embaixo das carteiras, outros abaixam a cabeça... Duas alunas começam a comparar os resultados que encontraram para a letra a) da lista de tarefas:

-Quanto deu sua letra a)?

\footnotetext{
${ }^{1}$ As discussões que aqui tomam corpo nascem de uma investigação que vem sendo realizada em uma escola municipal da cidade de Juiz de Fora, desde setembro de 2013. A pesquisa intitulada "Por uma Educação Matemática Menor: currículo e formação de professores junto à sala de aula de matemática" (CAPES/FAPEMIG, Processo $n^{\circ}$ APQ 03480-12) é coordenada por uma das autoras deste artigo. A outra autora desenvolve sua investigação de mestrado, com bolsa CAPES, nesse projeto. Todas as situações aqui apresentadas - falas de discentes e docentes, descrições de situações de sala de aula, entre outros - são oriundas das cartografias elaboradas junto à pesquisa e fazem parte do banco de dados do projeto.
} 
-Dezesseis. E a sua?

-Também. A gente deve ter acertado!

O professor faz a correção:

a) $4.1+3.2+2.3=4+6+6=16$

As alunas comemoram o acerto e comentam com o professor que diz: muito bem!.

Enquanto o professor começa a correção da tarefa seguinte, as meninas continuam a comparar suas respostas:

-A minha deu treze e a sua?

-A minha deu cento e setenta e dois.

As duas acham estranha a diferença no resultado e procuram verificar no quadro o resultado que o professor acabara de escrever.

$$
\begin{aligned}
& 1.2 .3+3.1+2.1 .1=6+3+4=13 \\
& -O \text { meu está certo. É treze! }
\end{aligned}
$$

Não percebendo porque o resultado fora diferente do que calculara, a garota fica em silêncio. Puxa seu caderno para bem perto de si, para que ninguém veja aquele resultado absurdo, muito distante da resposta correta. Dessa vez, não fala nada ao professor. A colega se esforça para continuar comparando os resultados, mas a menina já tratava de apagar todas suas resoluções seguintes e seguir copiando as corretas do quadro. Apressada nesses afazeres, não chega a questionar por que errara e nem a tentar decifrar as resoluções copiadas. A colega continua acertando as resposta e insiste em perguntar o que ela fez para encontrar 172. A aluna diz simplesmente que errou encerrando a conversa e tornando seu erro um mistério. Qual o caminho trilhado por aquela garota para encontrar tal resultado, tão distante da resposta correta?

Sob a aparente serenidade de uma pequena cidade, existe um mundo obscuro no qual os inocentes não ousam se aventurar e onde o imprevisto é normal. É o [um] reino assustador... (Sinopse do filme de David Lynch, Veludo Azul)

A tarefa ainda insiste:

Calcular $x y z+3 x+2 y z$, dados $x=1, y=2$ e $z=3$

Uma garota se arrisca e faz: 
$x y z+3 x+2 y z=123+3.1+2.23=123+3+46=172$

Estáfeito!

Puxa está errado.

Apagar!!!

Uma aluna se complica na matemática. Houve, então, um erro? A aluna errou ao fazer a tarefa solicitada? Apagar!!!

O acerto merece aplausos: muito bem, diz o professor. Já o erro, este deve ser eliminado: apagar, apagar, apagar...

\section{$* * *$}

O que fazer com o erro? Erro, que erro?

Na perspectiva da análise do erro, há a compreensão de que o erro é aquilo que

[...] na resolução de uma questão [...] não corresponde à produção esperada de um aluno (ou professor) que já deve ter tido contato com os conteúdos apresentados na referida questão ou com estratégias de resolução de problemas em Matemática. É, portanto, um referencial que toma como suposta verdade o conhecimento institucional, ou seja, o que a instituição "Escola" espera ver apresentado por alunos (ou professores) de um determinado nível de ensino, em suas produções escritas em Matemática (CURY, 2010, p. 02, destaque nosso).

Então, o erro, nesta perspectiva, acontece mediante uma expectativa dada pelo conteúdo matemático disciplinar escolarizado, organizado para aquela série ou ano na qual o aluno se situa. Erro como um não cumprimento de uma expectativa de ensino pelo professor. Um ensino e uma aprendizagem. Indissociabilidade ensino e aprendizagem. O erro como dissintonia entre o ensinar do professor e o aprender do aluno.

Na busca pelas causas dessa dissintonia, muitos caminhos vão sendo trilhados, numa procura por explicações: por que o aluno erra? Por que o aluno não aprende? Por que o professor não encontra êxito no seu ato de ensinar? Buscas por justificativas para esse chamado "fracasso" do ensino ou mesmo "dificuldades de aprendizagem" movem pesquisas e co-movem políticas curriculares. As questões ligadas ao ensino da matemática muitas vezes desdobram explicações didático-metodológicas e de formação de professores: há que se formar o professor para um ensino mais eficiente de matemática; há que se desenvolver novas metodologias e procedimentos didáticos. As questões ligadas à aprendizagem, muitas vezes, desdobram justificativas que pensam a aprendizagem tendo o aluno como seu centro. As psicologias da aprendizagem e do desenvolvimento cognitivo são acionadas para 
consubstanciar tais justificativas. Um olhar acerca das motivações do aluno e o desenvolvimento de procedimentos que facilitem a fixação de sua atenção e de sua motivação nos conteúdos que estão sendo ensinados também aparecem como uma discussão promissora.

Entre diferentes compreensões do erro no ensino e na aprendizagem da matemática e diversos modos de compreender o papel do erro neste processo, pesquisas se lançam na direção de enfrentamento dessas questões. A perspectiva da análise do erro, ao enfrentar estas questões, constitui um caminho para além da justificativa, proporcionando discussões sobre novas formas de ensinar um determinado conteúdo ${ }^{2}$.

Essas e outras tantas explicações e soluções povoam nossa educação matemática e são legítimas: muita pesquisa e muito estudo tem se pautado por este caminho. Aqui, lança-se a uma outra possibilidade, a de problematizar o erro enquanto tal. Que erro?

U**
Uma garota se arrisca e faz:
$x y z+3 x+2 y z=123+3.1+2.23=123+3+46=172$
Está feito!

O professor corrige e explica novamente: quando temos duas ou mais incógnitas juntas, significa que elas estão sendo multiplicadas uma pela outra. Veja por exemplo: $x y z$ significa $x$ vezes $y$ vezes $z$. Entendeu? Quando tem um número antes da letra é a mesma coisa: $3 x$ é igual a três vezes $x$. É assim que se opera em matemática, tá vendo? É só fazer sempre $\operatorname{assim} .$.

Uma aluna se complica na matemática. Um professor explica. Uma aluna apaga. E apaga. E apaga. E (se) apaga. E (se) apaga...

O que se dá aqui é uma não aprendizagem? A aluna não aprendeu. A aluna não consegue aprender: problemas de aprendizagem...

O que move o trabalho com a sala de aula? Isso: escola, currículo e matemática.

Só isso.

"Concluída a Educação Básica, menos de 30\% dos estudantes

\footnotetext{
${ }^{2}$ Helena Cury faz uma retrospectiva bastante ampla das produções relativas aos estudos do erro e à análise do erro, na área da Educação Matemática (CURY, 2007). Posteriormente, em 2010, a mesma educadora, em uma palestra durante o X ENEM, retoma este trabalho, ampliando aquele realizado anteriormente. Apesar de, segundo a própria pesquisadora, não se ocupar com um estudo exaustivo, naquele momento, trata-se de um trabalho importante para os estudos da área.
} 
dominam o conteúdo esperado em Língua Portuguesa. Em Matemática, esse percentual é de apenas 11\%". (Anuário Brasileiro da Educação Básica 2012 -

Editora Moderna)

-Acredita nessa doença?

Acredita?

Só isso: escola, currículo e matemática.

Escola sem o resto.

Currículo sem o resto.

Matemática sem o resto.

-Acredita nessa doença?

"Número de alunos reprovados em matemática em quatro turmas do sétimo ano em uma escola estadual no município de Juiz de Fora: 28”.

-Acredita nessa doença? Escola é resto! Currículo é resto! Matemática é resto!

E todo resto também o é!

-Acredita nessa doença? Senão é resto, o que é? Onde tem currículo fora do resto?

-Acredita nessa doença? Matemática, difícil de ensinar e de aprender. -Acredita?

Há doenças. Os sentidos estão adoecidos. Uma membrana cobre os olhos.

$\mathrm{O}$ paladar não saboreia.

O ouvido não ouve.

O olfato não cheira.

O tato, pele dura, espessa, tenta o impossível, ser impermeável. Outros sentidos sem nome também estão doentes por, e para, separar o restante: Da escola, do currículo, da matemática, do professor, do aluno... Modelos matemáticos. Modelos.

-Acredita nessa doença?

E o que resta? Aprendizagens.

Isso mesmo: APRENDIZAGEM da, e na, matemática. Tirando tudo, resta! Resta aprendizagem! -Acredita nessa doença? 
(SILVA, 2015, p. 29).

O erro, no mais das vezes nos processos educativos, é tratado por meio de medidas moralizantes relativas ao certo ou errado: dois caminhos, duas proposições. $\mathrm{O}$ acerto, aquilo que é capaz de apaziguar e constituir homogeneizações, é tratado com deferência, incentivado e demarcado como objetivo maior do processo de ensino da escola: o acerto significa que houve aprendizagem... Já o erro, ele se refere a uma falsa representação, um negativo do pensamento. No pensamento mais corriqueiro da educação tem-se, quase sempre, a compreensão de que o erro é dado por algo externo ao pensamento: uma desatenção ou uma incompreensão; uma explicação feita de modo equivocado, indevido ou incompleto pelo professor; uma dificuldade inata do aluno ("ele não consegue mesmo acompanhar o raciocínio matemático, tem dificuldades", não é incomum de se ouvir) ou da própria matemática em se fazer compreender ("matemática é difícil mesmo", ouve-se muitas vezes); dificuldades psicológicas ou cognitivas do aluno, ou problemas de ordem social, econômica... Problemas sempre extrínsecos ao pensamento.

\begin{abstract}
O erro vem de uma falsa representação - uma falha no bom senso que toma o senso comum de forma bruta - caracterizada por uma falha na percepção e pelo falso reconhecimento. Esse aspecto já tinha sido desenvolvido por Descartes, nas Meditações metafísicas, ao tratar das falsas percepções e dos erros dos sentidos. Assim, o erro não é intrínseco ao pensamento, mas, ao contrário, causado por algo que lhe é externo. Essa falha na percepção produziria um encadeamento "negativo" no processo de pensamento, pois o conduziria a falsas resoluções. Desse modo, a imagem dogmática do pensamento reduz o erro à figura do negativo (a besteira, a maldade e a loucura seriam reduzidas a essa figura), não aceitando as várias formas de pensar como um "pensar diferente" (GELAMO, 2008, p. 166).
\end{abstract}

A diferença, no pensamento representativo, é assassinada na medida em que ela, a diferença, é tratada como erro ou falsa representação. Como escapar deste pensamento representativo e garantir à diferença um lugar na diferença em si? Como manter o pensar diferente como diferença e não como simples erro que merece ser sumariamente apagado? Como tratar o erro como intrínseco ao pensamento, como possibilidade do próprio pensar e não como algo externo que desvia o pensamento do seu caminho natural e verdadeiro? Que matemática, então, vai sendo operada ali, como caminho possível àquele pensamento? 
Como uma educação matemática escolar, liberando-se do sentido de erro como extrínseco ao pensamento, mas tomando-o como desvio ${ }^{3}$ do pensamento e um modo mesmo de pensar, coloca-se a pensar a situação de sala de aula aqui em foco? Como se perguntar pelo sentido mesmo daquele pensamento?

Um jardim em sua normalidade: tranquilo, sereno... Surpresa: uma orelha cheia de formigas ${ }^{4}$. Chegando mais perto: quanto de mistério é capaz de suportar um jardim? Quanto de inusitado pode suportar uma orelha em um jardim? Mais de perto, as formigas levam a um submundo. Um mundo underground. Uma versão underground de mundo.

Uma garota se arrisca e faz:

$x y z+3 x+2 y z=123+3.1+2.23=123+3+46=172$

Está feito!

Uma sala de aula de matemática. Tudo parece correr como de costume. Uma orelha! Mais de perto: $x y z$ se torna 123. Cada letra se torna um algarismo. Algarismos se tornam número. Números que, quando operados, produzem um resultado, 172. Uma sala de aula de matemática suporta esse resultado? Suporta modos outros de operar e pensar junto à matemática?

Uma versão underground da matemática acontecendo na sala de aula?

\footnotetext{
3 “O desvio é do plano do sensível, da intensidade, dos gestos micro e dos mínimos detalhes. [...] O desvio é aquilo que pode resistir ao campo dos saberes, campo do institucional, campo do molar. O desvio é molecular, é átomo, é fluxão [...]" (GUARIENTI, 2012, p. 205).

${ }^{4}$ Há aqui uma referência ao filme Veludo Azul (Blue Velvet, 1986) do cineasta David Lynch e o seu "elogio do mínimo": "[...] o garoto protagonista da trama caminha pela pequena cidade interiorana de lumberton quando, num terreno baldio, no meio da grama, vê uma orelha humana. a câmara mergulha lentamente em direção a essa orelha. formigas "passeiam" por ela. a aproximação é total, como se a captura da imagem atravessasse o objeto capturado. a cena acontece após um desfile de cenas que mostram a pacata cidade, com sua vida corriqueira e normal, pessoas comuns e felizes quando o pai do protagonista sofre um infarto. é na volta de uma visita ao pai no hospital que o rapaz encontra a orelha. o mergulho e penetração da câmera na orelha faz descortinar o submundo da pacata cidade de lumberton" (Gallo, 2014, p. 25, todas as letras em minúsculo, conforme original).
} 
No lugar de rebatimento de imagens do pensamento universalmente válidas, um underground provoca o desmanchamento da forma, é a condição de sua problematização e a possibilidade de colocar o pensamento em exercício: não há, nesse espaço, um engajamento político fiado à natureza verdadeira do pensamento. A linguagem do underground não é a linguagem da solução de problemas e da constituição de imagens do pensamento, mas o próprio gaguejamento das soluções e das imagens. Uma linguagem que opera menos pela constituição de um conjunto de afirmações sobre uma imagem e mais se deixando estar em estado de questão: uma linguagem problematizadora, expressão da implicação da subjetividade no processo de conhecer matemática. Um exercício de pensamento. (CLARETO; CAMMAROTA, 2015, p. 67).

Um exercício do pensamento se coloca em uma sala de aula rompendo com o corriqueiro da pacata sala de aula de matemática: aproximando mais e mais: exercício de pensamento? Exercício de pensamento matemático?

Não poderia ser um simples desvio dos cálculos. Teria algo a mais. Um exercício de pensamento: engendrar pensar no pensamento.

Uma aluna se complica na matemática. Complicação que se dá no com, no comtato, no compartilhar, no comvocar, no com... Uma complicação. Um com. Um estar com: estar com a materialidade dos números, com a materialidade das quantidades, com a materialidade dos símbolos. O que emana dessa materialidade? Uma aprendizagem.

Aprender diz respeito essencialmente aos signos. Os signos são objeto de um aprendizado temporal, não de um saber abstrato. Aprender é, de início, considerar uma matéria, um objeto, um ser, como se emitissem signos a serem decifrados, interpretados (DELEUZE, 2010, p.4).

Que aprendizagem? Uma aprendizagem que coloca em suspensão a ideia de aprendizagem capturada pelo par ensino aprendizagem. Aprendizagem e ensino desassociados. Uma aprendizagem que não se dá como aquisição, mas como complicação, mais ainda, na implicação. Uma aprendizagem que se dá no estar com, implicar-se em.

Como xyz se torna 123? Como 123 se torna cento e vinte e três? Números como quantificadores? Números como símbolos? Que número? Número, numeral, quantidade, símbolo...

Na relação com a matemática, uma garota produz um modo de operar que não se descola da matemática. Produz uma fissura entre suas estruturas, opera junto à matemática 
produzindo um caminho outro. Letras tornam-se algarismos e esses tornam-se números; as operações são feitas produzindo um resultado: 172. O que esse resultado diz de matemática? E o que diz de aprendizagem?

Luta entre a borracha e o lápis em uma resolução que produz como resultado 172. Luta entre um apagar e um produzir. Luta que faz da resolução, um mistério, um desconforto.

Quanto mistério há no processo de aprender? "Nunca se sabe como uma pessoa aprende; mas, de qualquer forma que aprenda, é sempre por intermédio de signos, perdendo tempo, e não pela assimilação de conteúdos objetivos”. (DELEUZE, 2010, p.21)

Uma aprendizagem se dá junto à matemática. Um escape à reprodução de um modelo que se coloca como caminho que leva ao resultado correto. Invenção de um modo de operar que inquieta um pensamento, engendrando um pensar que rompe com um modo já normatizado, inaugurando um desvio como produção.

O que uma aprendizagem tem a ver com o certo ou errado de uma norma? Uma aprendizagem pode romper com um resultado correto?

\begin{abstract}
Dizendo de outro modo, aprender é sempre encontrar-se com o outro, com o diferente, a invenção de novas possibilidades; o aprender é o avesso da reprodução do mesmo. Segundo Deleuze isso se dá porque se aprender é relacionar-se com signos, eles, como problemas, pedem uma resposta e esta é sempre singular, inovadora. Cada um reage aos signos de uma maneira; cada um produz algo diferente na sua relação com os signos, o que equivale a dizer que cada um aprende de uma maneira, a seu modo singular. Ou seja, numa mesma aula, com um mesmo professor, múltiplas aprendizagens acontecem, na medida em que são múltiplos os alunos e que cada um aprende a seu próprio modo. A heterogeneidade de que fala Deleuze é esta multiplicidade. É por esta razão, por ser relação, que o signo implica em heterogeneidade, em diferença, e não em mesmidade, na contramão dos esforços de toda a pedagogia escolar com sua maquinaria de serialização, de produção de subjetividades em série (GALLO, 2012, p.8).
\end{abstract}

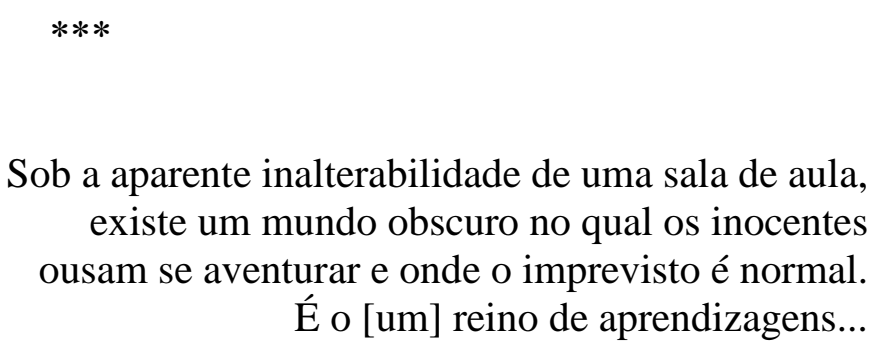

No submundo das salas de aulas, as aprendizagens ocorrem enquanto produções. As relações com a matemática se multiplicam nas singularidades. Sob a aparente inalterabilidade de uma sala de aula essas relações imbricam-se como insetos se misturando com o barro sob a 
grama ${ }^{5}$. Um mínimo e sua potência. Aprendizagens como orelhas em um jardim que não são quantificadas ou qualificadas como acertos. Cena de uma orelha cheia de formigas em um jardim que se faz com o mergulho da câmera, com movimento.

Movimento de uma cena em uma sala de aula junto a uma produção: $x y z+3 x+$ $2 y z=123+3.1+2.23=123+3+46=172$. Uma aprendizagem que vai se dando no contato com os signos. Quem aprende a nadar compõe no contato com a água. Inventa um corpo nadador junto à água ${ }^{6}$. Assim também no contato com a matemática um corpo aprendiz se faz enquanto opera em sua materialidade. Os movimentos do professor não asseguram o nadar do aprendiz. A explicação do professor também não é capaz de proteger de uma complicação com a matemática. São composições que vão se dando e são capazes, por vezes, de promover implicações com a matemática.

O que fazer, pois, com uma orelha cheia de formigas? Ou melhor, o que uma orelha cheia de formiga faz, produz? Produz efeitos múltiplos em uma paisagem, em um jardim: a orelha deixa de ser orelha humana e passa a se constituir como componente de um jardim, casa de formigas, alimento de insetos... Quanto de inusitado guarda o submundo de um jardim?

Uma sala de aula: um professor, vários alunos e alunas, um currículo prescrito por políticas públicas, um currículo praticado pelo professor, currículos vivenciados e produzidos por alunos, um livro didático, uma lista de tarefas... pensares, quereres, sentires... aprendizagens. Quanto de inusitado guarda o submundo de uma sala de aula de matemática?

\footnotetext{
${ }^{5}$ Cena do filme Veludo Azul: A cena inicial é um presságio do que está no superficial: um jardim florido com rosas e margaridas, um bombeiro estático acenando para a câmera, uma cerca branca com um céu azul de fundo. Por fim vemos o podre. Por trás de toda a beleza cultivada nos jardins da vizinhança, há vários insetos se misturando ao barro. O que há abaixo de tantos artifícios? Se a grama já esconde seus próprios segredos, o que escondem os complexos seres humanos em todos os seus sentimentos e ações e distúrbios? (NEVES, 2011, s/d).

${ }^{6} \mathrm{O}$ movimento do nadador não se assemelha ao movimento da onda; e, precisamente, os movimentos do professor de natação, movimentos que reproduzimos na areia, nada são em relação aos movimentos da onda, movimentos que só aprendemos a prever quando os apreendemos praticamente como signos. Eis por que é tão difícil dizer como alguém aprende: há uma familiaridade prática, inata ou adquirida, com os signos, que faz de toda educação alguma coisa amorosa, mas também mortal. Nada aprendemos com aquele que nos diz: faça como eu. Nossos únicos mestres são aqueles que nos dizem "faça comigo" e que, em vez de nos propor gestos a serem reproduzidos, sabem emitir signos a serem desenvolvidos no heterogêneo. (DELEUZE, 2006, p. 48).
} 
Quanto de aprendizagem suporta um não aprender? As "dificuldades de aprendizagem", as reprovações, as inadequações, os erros, o apagar... Um movimento de olhar de perto, de colocar-se a ouvir, ver e sentir, compartilhar, negociar, falar, escutar, sensibilizar... Um tal movimento pode agenciar aprendizagens outras em uma sala de aula? Quanto de aprendizagem acontece no underground da sala de aula?

\section{Referências}

Anuário Brasileiro da Educação Básica. Todos pela educação. São Paulo: Moderna, 2012. Disponível em: <http://www.todospelaeducacao.org.br/biblioteca/1450/anuario-brasileiroda-educacao-basica> Acesso em: 15 jan. 2015.

CLARETO, S.; CAMMAROTA, G. G. Professores de Matemática em formação: invenções e (sub)versões. In: D’AMBROSIO, B.; LOPES, C. (Org.). Ousadia Criativa nas Práticas de Educadores Matemáticos. Campinas: Mercado das Letras, 2015. p. 65-86.

CURY, H. N. Análise de erros: o que podemos aprender com as respostas dos alunos. Belo Horizonte: Autêntica, 2007.

CURY, H. Análise de Erros. In: ENCONTRO NACIONAL DE EDUCAÇÃO MATEMÁTICA, $10^{\circ}$, 2010, Salvador. Anais... Salvador: SBEM, 2010. p. 01-11.

DELEUZE, G. Diferença e repetição. Tradução de L. Orlandi e R. Machado. 2.ed. Rio de Janeiro: Graal, $2^{\mathrm{a}}$ ed., 2006.

DELEUZE, G. Proust e os Signos. Tradução de . A. C. Piquet e R. Machado. 2.ed. Rio de Janeiro: Forense Universitária, 2010.

GALLO, S,. mínimo múltiplo comum. In: RIBETTO, A. (Org.). políticas, poéticas e práticas (com minúsculo). Rio de Janeiro: Editora Lamparina/FAPERJ, 2014. p. 20-33.

GALLO, S. As múltiplas dimensões do aprender... In: CONGRESSO DE EDUCAÇÃO BÁSICA: APRENDIZAGEM E CURRÍCULO. 2012, Florianópolis. Anais... Florianópolis, 2012. p. 01-10. Disponível em:

<http://www.pmf.sc.gov.br/arquivos/arquivos/pdf/13_02_2012_10.54.50.a0ac3b8a140676ef8ae0dbf3 2e662762.pdf >. Acessado em: 15 ago. 2013.

GELAMO, R. P. Pensar sem pressupostos: condição para problematizar o ensino da filosofia. Revista Pro-Posições, Campinas, v. 19, n. 3(57), p. 161-174, set./dez. 2008.

GUARIENTI, L. B. O. A potência do espaço como desvio no aprender dos corpos deambulantes.

Geograficidade, v. 2, n. especial, p. 202-217, 2012.

NEVES, G. Crítica do filme Veludo Azul. 1986. Disponível em:

<http://criticamecanica.blogspot.com.br/2011/08/veludo-azul-1986.html>. Acesso em: 28 jun. 2015. 
SILVA, A. Contos em uma formação: currículo e matemática como acontecimento na sala de aula. 2015. p. 01-40. Exame de Qualificação de Mestrado (Programa de Pós-Graduação em Educação) Universidade Federal de Juiz de Fora, Juiz de Fora, 2015.

Submetido em Junho de 2015. Aprovado em Abril de 2016. 